\section{Letter from Field}

\section{Check for updates}

\title{
New law on prevention and control of alcohol related harms in Vietnam
}

\section{Kidong Park (D)}

World Health Organization Vietnam, Hanoi, Vietnam

Editor's note: Dr. Kidong Park is the World Health Organization (WHO) Representative in Viet Nam.

On 14 June 2019, the National Assembly of the Socialist Republic of Vietnam approved the law on prevention and control of alcohol-related harm which will be effective from the 1st of January 2020.

\section{ALCOHOL USE IN VIETNAM}

Alcohol use in Vietnam is currently at a high level and has dramatically increased over the years, demonstrated by 3 indicators: alcohol per capita consumption level, prevalence of lastmonth drinkers, and prevalence of heavy episodic drinking (HED). The annual consumption level per capita of pure alcohol by adults (age 15 and older for both genders) has increased from 3.8 litres in 2004 to 4.7 litres in 2010, and further to 8.3 litres in 2016. It means that every Vietnamese adult drank about 467 bottles of beer per year in 2016. It was much higher than global average of 6.4 litres. Other countries in the Western Pacific Region consumed much less than Vietnam-Mongolia 7.4 litres, China 7.2 litres, Cambodia 6.7 litres, the Philippines 6.6 litres and Singapore 2 litres. World Health Organization (WHO) also forecasts that this consumption level will further increase to 9.9 litres by 2020 and 11.4 litres by 2025 in the absence of effective interventions to control the harmful use of alcohol. ${ }^{1}$ Prevalence of last-month drinkers has increased from $69.6 \%$ in 2010 to $80.3 \%$ in 2015 for men between the ages of 25 and 64 , and from $5.6 \%$ to $11.2 \%$ from women in the same age bracket. Prevalence of HED among Vietnamese adult male has increased from $25.1 \%$ in 2010 to $44.2 \%$ in 2015. ${ }^{2}$

In addition, alcohol consumption in Vietnamese adolescents is at an alarming level and increasing. According to the national survey of adolescents and youths in 2008, approximately $80 \%$ of young men and $36.5 \%$ of young women aged $14-25$ years used alcohol, an increase by $10 \%$ among males and $8 \%$ among females over 5 years. Some $60.5 \%$ of young males and $22 \%$ of young females had ever been intoxicated. It is notable that prevalence of underage drinking - drinking (14-17 years) - is high at $47.5 \%$ for both sexes. The $67 \%$ of young people aged 18-21 years used alcohol. ${ }^{3}$ According to a 2013 school-based student health survey, $52.7 \%$ of students in the 8 th to 12 th year of school had ever used alcohol, 
among them, $43.8 \%$ drank their first glass of beer or wine/spirits before age 14 and $22.5 \%$ had been intoxicated at least once. ${ }^{4}$

\section{CONSEQUENCE OF ALCOHOL USE IN VIETNAM}

Vietnam is facing increasingly severe growth in non-communicable diseases (NCDs). In 2016, the country recognized 549,000 deaths for all causes, of which fatal NCDs accounted for $77 \% .^{5}$ According to research on the global burden of disease in 2016, $12 \%$ of deaths in Vietnam are associated with alcohol use. ${ }^{6}$

Alcohol-related road crashes in Vietnam account for $32.4 \%$ of total road crashes in men and $19.6 \%$ in women. An analysis of survey data of 1,061 deaths due to road crashes in Vietnam shows that one fifth of deaths due to road crashes are caused by alcohol use. ${ }^{7}$

Social harm from alcohol drinking in Vietnam is highly prevalent. Of married women or those living with their partners, $32.5 \%$ experienced some form of harm from their partner's or husband's heavy drinking. Further, $21 \%$ of parents/caregivers said that children in the family suffer harm from the drinking of others. ${ }^{8}$

\section{WHO'S SUPPORT TO CONTROL HARMFUL USE OF ALCOHOL IN VIETNAM}

With an aim to curb the harmful use of alcohol, WHO published the Global Strategy to Reduce the Harmful Use of Alcohol which recommended evidence-based interventions in 2010. ${ }^{9}$ In 2017, WHO released a new technical package called SAFER which outlined 5 high-impact strategies that can help governments in addressing the harmful use of alcohol. ${ }^{10}$ WHO conducted cost-effective analysis and identified 3 best buys to curb harmful use of alcohol (most cost-effective interventions which cost less than International $\$ 100$ per disability adjusted life year averted in low- and middle-income countries): increasing excise taxes on alcoholic beverages; enacting and enforcing bans or comprehensive restrictions on exposure to alcohol advertising, across multiple types of media; and enacting and enforcing restrictions on the physical availability of retailed alcohol. ${ }^{11}$ WHO further advocated that every US dollar invested in implementing best-buy strategies, the return is US $\$ 9.13 .{ }^{12}$

WHO's advocacy to curb harmful use of alcohol in Viet Nam started in early 2012. In June 2017, the National Assembly of Viet Nam approved the proposal from the Government to start drafting process of new alcohol control law. The Government of Viet Nam then assigned the Ministry of Health to lead the drafting process. Alcohol industry also started their lobby to nullify or at least delay the law-making process. Their arguments tackled every aspect of alcohol control measures and alcohol consumption cultures such as the law should focus on treatment of alcohol use disorder only, beer is less harmful than liquors, the government should improve the quality of home-made traditional liquor only, limiting alcohol beverage promotion is violating international law, alcohol control law will have negative impact on economy, etc.

In July 2018, Dr. Shin Young-soo, the WHO Regional Director for the Western Pacific, issued a letter highlighting above-mentioned 3 bet buys to the highest level of government officials 
(the Prime Minister and the Chairperson of the National Assembly) in making decision in approving the draft law on prevention and control of alcohol-related harm. In September 2018, the draft law was submitted by the Government to the National Assembly for first round of debate during the fall session of the National Assembly. The outcome of first round debate was supportive to the draft law. The National Assembly requested the Government to submit the final draft of the law to its spring session in 2019.

Lobby from alcohol industry became very tough. They wanted either to nullify the law or at least weaken key articles of the law. The author, WHO Representative in Vietnam, issued a few letters and statements to advocate urgent need to control harmful use of alcohol in Vietnam and scientific evidence of intervention measures. The advocacy activities included media interview, Op-Ed, social media campaign, etc. In April 2019, the author provided a statement to the Foreign Affairs Committee of the National Assembly on the international practice of alcohol control measures. The author argued that the provisions of the Law on Prevention and Control of Alcohol Related Harm do not hinder the proper application of international treaties for the following reasons: as the law does not specify any discriminatory treatment between national goods and imported goods, it is in compliance with International regulations; the World Trade Organization (WTO) Members States have the right to determine the level of health protection they deem appropriate as public health was a "legitimate objective" in light of WTO exceptions to free trade; and under the Technical Barrier to Trade Agreement, all member states have the right to restrict trade to achieve "legitimate objectives," such as the protection of public health. In order to establish this legitimacy, "available scientific and technical information" need to be demonstrated. And, alcohol harm on health is widely proven scientifically.

In April 2019, WHO together with the Ministry of Health in Vietnam organized a public workshop to advocate the law. The author argued that "Alcohol-related harm does not depend on the type of beverage. Alcohol-related harm depends on the total volume of drinking ethanol and the pattern of drinking. The amount of pure alcohol drinking is same for one glass of $4 \%$ beer $(330 \mathrm{~mL}$ ), one glass of $13.5 \%$ wine $(100 \mathrm{~mL}$ ) and one cup of $40 \%$ spirit (30 $\mathrm{mL}$ ). There should be no exception in regulating alcohol marketing based on alcohol type." WHO also published the "Questions and Answers on Prevention and Control of Alcoholrelated Harm" in April 2019.

In late April and early May 2019, there were 2 tragic drinking driving traffic accidents in Hanoi. These claimed the lives of 3 middle-age women, who were the mainstays of their family and children living under extreme difficulties. On Sunday morning in May, about 8,000 Hanoi citizen gathered and marched down the walking street around Hoan Kiem Lake, an iconic site of Hanoi to raise awareness and call for real action against drink-driving in Vietnam.

The campaign was organised by the National Traffic Safety Committee, the Hanoi People's Committee, accompanied by the Vietnam National Drama Theatre and Hanoi 1991-1994 High School Alumni Community. WHO also joined the campaign.

These last advocacy efforts changed opinion of Vietnamese people on the law. Finally, the National Assembly approved the law without any major amendment from the draft submitted by the Government. 


\section{NEW ALCOHOL CONTROL MEASURES IN VIETNAM EFFECTIVE FROM 1 JANUARY 2020}

The new law ensures stronger restrictions on alcohol marketing and sets limitations on the physical availability of retailed alcohol products, among others. The following 3 best-buys for preventing alcohol-related harms recommended by WHO sets the tone of the new law: bans or comprehensive restrictions on exposure to alcohol advertising; restrictions on the availability of retailed alcohol; and excise tax on alcoholic beverages. Upon implementation of the new law, advertising of alcohol products will be banned from 6:00 to 9:00 p.m., every day. Advertisements will also have to carry warnings on alcohol-related harms. In addition, there will be a ban on marketing strategies that involve corporate giveaways, images, logos, music, film talents, and other product brands targeting people under 18. In terms of limiting alcohol availability, establishing new on-site alcohol consumption businesses within 100 meters from health care facilities and schools will be prohibited as well with the new law in place. In the same way, selling alcohol to people under 18 years old will be banned. In terms of fiscal measures, the National Assembly decided that the proposal to raise alcohol price would be discussed within the premise of a separate law on taxation.

The new law also adopted a strict no drink-driving policy measure. Drink-driving will be completely prohibited for both car and motorcycle riders. In addition, the following actions are will be prohibited: inciting, encouragement and forcing other people to drink beer/ alcohol; drinking beer/alcohol before and during working hours by public officials, students, members of the armed forces; employing people under 18 years of age in the production, trading of alcohol/beer.

As mentioned by Dr. Nguyen Thị Kim Tien, the Minister of Health of Vietnam, at a workshop to discuss full implementation of the law on prevention and control of alcoholrelated harm, this is the first time Vietnam has a complete and comprehensive law on alcohol and beer prevention and control. It is also a very complicated one as it related to habits and behaviours of people. To bring this law into everyday life and ensure its feasibility and effectiveness, activities to disseminate and implement the law are very important. To effectively prevent alcohol-related harms, this law must be strictly implemented with support from all levels of the Government as well as the public. Vietnam should allocate adequate funds and human resources for implementation of the law; raising public awareness, involve NGOs and partners in the implementation and monitoring of the law to ensure transparency and effectiveness and promoting community initiatives for the prevention of harmful use of alcohol.

\section{REFERENCES}

1. World Health Organization. Global Status Report on Alcohol and Health 2018. Geneva: World Health Organization; 2018.

2. Department of Preventive Medicine, Ministry of Health (VE). National Survey of Vietnam Non-communicable Disease Risk Factors 2015. Hanoi: Ministry of Health; 2015

3. General Statistics Office of Vietnam. Second National Survey of Vietnamese Adolescents and Youth: Report on the Use of Alcohol and Tobacco among Vietnamese Youth. Hanoi: General Statistics Office of Vietnam; 2010.

4. World Health Organization; Centers for Disease Control and Prevention. Global School-based Student Health Survey: 2013. Geneva: World Health Organization; 2014. 
5. World Health Organization. Noncommunicable Diseases Country Profiles 2018. Geneva: World Health Organization; 2018.

6. Institute for Health Metrics and Evaluation (US). Global burden of diseases study. http://vizhub. healthdata.org/gbd-compare/. Updated 2016. Accessed November 5, 2019.

7. Ngo AD, Rao C, Hoa NP, Hoy DG, Trang KT, Hill PS. Road traffic related mortality in Vietnam: evidence for policy from a national sample mortality surveillance system. BMC Public Health 2012;12:561. PUBMED | CROSSREF

8. Callinan S, Rankin G, Room R, Stanesby O, Rao G, Waleewong O, et al. Harms from a partner's drinking: an international study on adverse effects and reduced quality of life for women. Am J Drug Alcohol Abuse 2019;45(2):170-8. PUBMED | CROSSREF

9. World Health Organization. Global Strategy to Reduce the Harmful Use of Alcohol. Geneva: World Health Organization; 2010.

10. World Health Organization. SAFER: Preventing and Reducing Alcohol-related Harms. Geneva: World Health Organization; 2018.

11. World Health Organization. Tackling NCDs: Best Buys and Other Recommended Interventions for the Prevention and Control of Noncommunicable Diseases. Geneva: World Health Organization; 2017.

12. World Health Organization. Saving Lives, Spending Less: a Strategic Response to Noncommunicable Diseases. Geneva: World Health Organization; 2018. 